\title{
La guerra en la sierra central y la independencia controlada en Lima
}

Recibido: 27/03/2021

Aprobado: 30/06/2021

Publicado: 31/07/2021

\author{
GUSTAVO MONTOYA RIVAS \\ Universidad Nacional Mayor de San Marcos (UNMSM) \\ gmontoyarivas@yahoo.es \\ https://orcid.org/0000-0002-1597-6239 \\ YIZZA DELGADO NERY DE VITA \\ Universidad San Ignacio de Loyola (USIL) \\ Universidad Nacional Mayor de San Marcos (UNMSM) \\ yizza.delgado@usil.pe \\ https://orcid.org/0000-0001-9193-7453
}

V. E. había venido dexando en el Asia el nombre antiguo de Moisés, y recibió el nuevo de San Martín

CDIP $^{1}$

Las teorías no son delitos BERNARDO MONTEAGUdO ${ }^{2}$

\section{RESUMEN}

Este artículo se ocupa de representar las circunstancias ideológicas, políticas y militares del inicio de la guerra por la independencia en la sierra central, con el énfasis puesto en la participación de actores sociales rurales. Y, de otro lado, presenta el proceso político en Lima durante el Protectorado y los desafíos que hubo de enfrentar antes de su caída en septiembre de 1822. También se propone establecer los diferentes matices con que se desarrolló la guerra en ambos escenarios.

Palabras clave: alcaldes constitucionales, guerra, cultura política, protectorado, expedición libertadora

\section{The war in the Central Sierra and the controlled independence in Lima}

\begin{abstract}
This article addresses the ideological, political, and military circumstances at the start of the war for independence in the Central Sierra, with emphasis on the participation of social actors in rural areas. Conversely, it presents the political process in Lima during the Protectorate, and the challenges it had to face before its fall on September of 1822. It also intends to establish the different nuances of the war as it unfold in both places.
\end{abstract}

Keywords: constitutional mayor, war, political culture, protectorate, liberating expedition

$1 \quad \operatorname{CDIP}(1971, \mathrm{t} . \mathrm{V}$, vol.1, 32).

2 CDIP (1971, t. XIII, vol. 2, 289). 
H n el extenso y complejo escenario territorial de conflictos sociales armados, desatado por la presencia del ejército libertador en la sierra central, es posible hallar diversas modalidades de resistencia y/o adhesión a las promesas de la patria. Los pueblos y los grupos sociales que los conformaban intervinieron en el conflicto desde distintas estrategias y apelando a diversos instrumentos de intervención. Destaca justamente el ingreso de la plebe rural peruana en la guerra desde consideraciones aún poco exploradas por la historiografía.

Alejados de las narrativas tradicionales, que insistían en naturalizar el patriotismo de los sectores populares andinos, las recientes investigaciones regionales sobre la guerra vienen demostrando la existencia de una cultura política y de una memoria histórica, densa y compleja justamente entre los dominados y explotados, que se remonta a la Gran Rebelión (Walker 2016, Spalding 2016). Este sofisticado entramado ideológico da cuenta de una cartografía mental que apenas se está empezando a desmontar. Una atenta lectura de la documentación de la época sugiere la emergencia de una lexicografía y de un vocabulario político que ya anuncia el posterior protagonismo de estos grupos sociales en la región de los Andes centrales, a todo lo largo del siglo $\mathrm{XIX}^{3}$

Se trata del protagonismo de los alcaldes constitucionales y el prestigio social que exhibieron ante las autoridades patriotas impuestas por un ejército de ocupación (Escamilla 2013; Sala i Vila 1993, 2011). Si bien se ha señalado que una de las modalidades de intervención de la plebe en la guerra fue por la preservación de intereses locales y comunales aún estas siguen siendo generalizaciones que no se sostienen sobre una casuística consistente. Que los alcaldes hayan liderado e invocado el respeto y la preservación de sus fueros en un escenario de conflicto armado, y con la presencia de un ejército de ocupación, y teniendo de otro lado presente que las armas del rey estaban ahí para que no olvidaran el lugar que ocupaban en la estructura social del sistema de dominio colonial tardío, dice mucho de la cultura política que poseían y de la sagacidad con que maniobraron. Y esta cultura política también merece ser conocida, y no como una secuela marginal de la guerra sino como lo que fue para sus protagonistas (Sala i Vila 2011): las coordenadas ideológicas que tejieron y desde donde ingresaron y vivieron la guerra. Por ello la necesidad

3 Aunque la bibliografía es extensa, aquí cabe mencionar a los siguientes autores: Méndez (2014), Ige (2008), Quiroz (2015), Pereyra (2016) y Glave (2005). 
de conocer cómo traspusieron un conflicto al que lo vieron como ajeno, pero al que tuvieron que racionalizarlo desde sus intereses (Montoya 2020).

En el análisis que propone este texto, nuevamente aparece la figura de San Martín ocupando una centralidad decisiva. ${ }^{4}$ En efecto, fue en torno a su figura en que se fueron congregando las más diversas y disímiles modalidades de justificación ideológica, acciones militares, disidencias y adhesiones políticas entre vastos sectores sociales en esta región. Desde entonces, con la presencia del Ejército Unido de los Andes, y en nombre de la patria, se ensayó toda una serie de modalidades de intervención en la guerra por parte de los pueblos. La retórica patriota daba pábulo a un amplio abanico de argumentaciones entre grupos sociales heterogéneos que hallaban en ese idealismo político la convenida justificación a sus acciones. Esas promesas que iba desperdigando por ahí el aparato de propaganda patriota ahora encontraban a sus interlocutores andinos más disímiles y audaces.

Así, se puede encontrar una queja interpuesta por las autoridades principales y alcaldes de Huarochirí (CDIP 1971, t. V, vol. 1, 321-323) en contra de tres comandantes guerrilleros patriotas. El conflicto desatado fue a raíz de la captura por parte de quince indios de Huarochirí del correo realista que pasaba por sus territorios. Este correo luego fue violentamente confiscado por los comandantes guerrilleros, lo que impidió que fuesen las autoridades locales las que entregasen lo capturado al Estado Mayor patriota. Pero este argumento - aparentemente trivial - que da lugar al escrito, apenas es la cáscara de varios conflictos generados precisamente por la guerra ya instalada en esta región. Desde el inicio se identifica la filiación étnica de los protagonistas de esta, digamos, operación comando indígena: "fueron 15 Indios nuestros de aquí hasta las cercanías de la Doctrina de Chilca donde apresaron al correo de Arequipa y sus tres cargas que nos parece se componen de ropas, cartas y 7 pesos en plata" (CDIP 1971, t. V, vol. 1, 321). Por lo que se lee, la parte más valiosa del botín es sin duda la correspondencia. ¿La leyeron? ¿Qué decía?

Sigamos extractando lo más sustancial del documento. A continuación, señalan que su propósito era entregar — al comando militar patriota se entiende - lo más rápido posible lo que habían capturado. Sin embargo, continúan los alcaldes: "Pero nuestros proyectos sencillos hasi frustrados los muy zelosos, señores Comandantes Don Joaquin Cordero, Don Ignacio Ninavilca y el Señor Mayor Don Isidoro Villar" (CDIP 1971, t. V, vol.1, 321). Es de anotar

4 Sobre la presencia de San Martín en la sierra central, puede consultarse los artículos contenidos en el libro sobre La expedición libertadora (IEP y UNMSM), próximo a publicarse. 
que Cordero, Ninavilca y Tellez ostentaban sendas comisiones, cuya fuente de legitimidad era el ejército libertador. Se trataba de jefes guerrilleros que contaban con tropas locales bajo su mando. ${ }^{5} \mathrm{Y}$ fue justamente esa legitimidad la que fue cuestionada a propósito de este conflicto. De los nombrados, Ninavilca es el más recriminado y a quien responsabilizan por los atropellos $\mathrm{y}$ violencia que se cometiera en contra de los huarochiranos:

Ninavilca vino desde Muyupampa con comisión del Señor Mayor para llevarse las dichas cargas, para llevarlas mando que sus soldados carguen y preparen las armas, y el con sable en mano nos mando le presentemos las bestias que habían de llevar toda nuestra presa: y porque tardamos algo en presentarle las bestias porque anduvimos buscando escusas por no entregarles las cargas, esgrimió su brazo dando sablazos a los que podía de modo, que a dos personas les estrujo demasiado y dejo a varios heridos, de forma que unos no pueden andar, y otros tienen el brazo sin acción, fue tan tenaz en maltratarnos que a José Maria Tello ${ }^{6}$ le persiguio a sablazos el espacio de dos cuadras hasta que le hirió, en vano se le reconvenía para que sese sus excesos, pues contestaba que nos había de abalear según el orden que tenia para eso (CDIP 1971, t. V, vol. 1, 322).

¿Por qué buscaban excusas para no entregar a Ninavilca lo capturado a los realistas? Por lo que señalan, se refieren a este como ajeno y extraño a su comunidad. Y esto es lo que interesa: la cohesión que exhiben, siempre que se opongan a "otros". Pero, además, deslizan que la violencia ejercida por Ninavilca era en realidad una orden que este había recibido de los patriotas, lo cual distancia a los dirigentes de Huarochirí de los libertadores. O por lo menos deslizan un reclamo frente a la orden que exhibió Ninavilca de parte del ejército libertador patriota para "abalearlos".

La actitud de los alcaldes de Huarochirí se hace más dura en lo respectivo a la resistencia que ofrecen, no solo a Ninavilca, sino que, por intermedio de este, al propio Álvarez de Arenales, y lo que representa: el militar de mayor graduación y bajo cuya dirección estaban subordinadas todas las operaciones militares y políticas en la región. Efectivamente, Álvarez de Arenales ya se había enterado y estaba al corriente de la captura del correo dos días antes, por

5 De Joaquín Cordero, señala Arenales en carta a Miguel Otero en una fecha tan temprana como marzo de 1820 que "Anoche fui a ver a sargento mayor don Joaquín Cordero, que me hizo llamar de Antahuaro, distante tres leguas sobre estye rio a donde había venido con 60 hombres" (CDIP 1971, t. V, vol. 1, 268).

6 José María Tello no era ningún personaje desconocido. Un año después aparece como un próspero hombre de negocios operando en la capital durante el protectorado. Pero, además, aparece comprometido en un supuesto ardid con su antiguo adversario Ninavilca. Este último había intentado manipular y ganarse el favor de los alcaldes indígenas a fin de obtener su nombramiento como gobernador de la provincia (CDIP 1971, t. V, vol. 2, 206-207). 
lo que expresamente había enviado una orden "A los principales y alcaldes de las comunidades de la doctrina de Huarochirí” (CDIP 1971, t. V, vol. 1, 318), en términos que no daban lugar a interpretaciones:

dirigo la correspondiente providencia al Gobernador y Capitán Don Ignacio Ninavilca, ordenandolo lo que debe hacer con el correo apresado, cargas, correspondencia e intereses, por todo lo demás; debiendo ustedes tener entendido que en semejantes casos, debe poner cuanto le tome a disposición de sus comandantes, obedeciéndolos siempre; pero que si dan lugar con semejantes desobediencias a dicho comandante se tomaran serias providencias contra los revoltosos, inquietos y arbitrarios (CDIP 1971, t. V, vol. 1, 318).

Queda claro entonces que los alcaldes no solo se resisten, sino que subvierten lo ordenado por Álvarez de Arenales. El punto aquí es que si lo hicieron fue porque calcularon que era posible imponer sus fueros y hacer uso de la delegación de poderes recientemente recuperados. ${ }^{7}$ Otra lectura plausible es que no veían ninguna contradicción entre los derechos emanados de la Constitución recientemente puesta en vigor y las promesas de los patriotas. ¿Acaso ambos proyectos no los tenían a ellos, a los indígenas peruanos, como a sus beneficiarios preferenciales? ¿Y esta conducta no expresa una sagaz - por no decir sofisticada - táctica que proviene de una memoria histórica específica y que en ese momento era puesta en movimiento una vez más para preservar sus intereses?

De otro lado, es de suyo bastante expresivo que Ninavilca, un prominente personaje social de la región de Huarochirí y acaudalado comerciante, tenga opositores tan encarnizados, sobre todo si se repara que aquellos que lo acusan se identifican como colaboradores de los patriotas. En realidad, en esta fecha temprana, como fue el mes de junio de 1821, el liderazgo patriota de Ninavilca aún no estaba consolidado, lo que también expresa los conflictos internos entre las poblaciones indígenas para acceder a posiciones de poder vía prestigio social o colaboracionismo con las armas de la patria. Los antecedentes que ofrecen de Ninavilca no son nada prometedores en lo concerniente a su identidad política:

Este hombre vivía relativamente en la Doctrina de Chontay asomó aquí aora seis meses huyendo de los realistas, y cuando nosotros saliamos a rechazar a esos realistas de aquí se fue corriendo a Yauli huyendo aun de nosotros mismos;

7 Peralta $(2010,2018)$ ha demostrado la velocidad con que la elite indígena aprovechó en su beneficio toda la legislación gaditana. 
ahora vuelve contra nosotros mas furioso que un loco: este es el que sin hacernos nombramiento de ser Gobernador de esta nuestra Provincia nos ha impelido que le sirvamos como á ídolo (CDIP 1971, t. V, vol.1, 322).

La resistencia de estos alcaldes constitucionales y del pueblo de Huarochirí al que representan es en contra del reciente nombramiento de Ninavilca como nueva autoridad impuesta por el ejército de ocupación. Esa es la madre del cordero: el conflicto desatado entre grupos antagónicos en el seno de un territorio tan importante como Huarochirí. Es decir, los alcaldes de Huarochirí utilizan su investidura, que proviene del anterior régimen, y la oponen al nuevo poder patriota. Que retraten a Ninavilca como a un convenido no suma ni resta a la base de su poder social e identidad comunitaria, enfrentada ahora sutilmente — como se verá más adelante — a los patriotas en la figura de Ninavilca y oponiéndose a los realistas, de quienes precisamente buscan distanciarse exhibiendo como trofeo la correspondencia capturada. De otro lado, al denunciar las pretensiones de Ninavilca de querer ser tratado como un "ídolo", estos alcaldes dejan muy en claro el carácter comunal desde donde fluye la legitimidad de su poder. Es una ruptura de la noción de autoridad que le precedía y una incorporación de la nueva jerga política ya puesta en movimiento, por lo menos desde los acontecimientos acaecidos en Huánuco en 1812.

Extendiéndose en la conducta violenta y autoritaria del comandante militar patriota, señalan que:

mando pocos días há que chicos y grandes todos fuésemos a Muyupampa, donde el estaba so pena de 50 azotes y 6 pesos que imponía de multa al que no obedeciese aquel mandato, el que luego que llego aca empeso a beber hasta la noche mandando poner guardas de soldados a la puerta, y que los Alcaldes le asistan y sirvan en sus escándalos, siguió bebiendo, y entretanto, porque el violinista cansado de tañer cesó le despedazo el violin e hirió su persona a sablazos. Para nuestro Gobierno es necesario saber si V.E. aprueba que este Ninavilca sea nuestro Gobernador... Si dice que si, alegres nos someteremos diciendo: Amén (CDIP 1971, t. V, vol. 1, 322).

Si retrataban a Ninavilca en términos tan negativos era porque por intermedio de aquel expresaban sus reservas y hasta el desconcierto que les generaban las promesas de la patria. Hay otra cuestión aquí que es necesario señalar. Ahí cuando censuraban a Ninavilca en términos morales, lo que estaban expresando era justamente el contenido moral que reclamaban de la patria y que, por lo tanto, Ninavilca debía observar, dada su condición de patriota. Pero quizás 
lo que más les preocupaba a los alcaldes era dejar muy en claro la autoridad y el gobierno que ejercían. Estas autoridades no tenían ningún reparo en exhibir los atributos de la soberanía que ejercían "nuestro gobierno", según afirman. Dirigido a San Martín, el documento fue firmado por los dos alcaldes respectivos de Huarochirí: H. S. Clemente Cajahuaringa, Tomás Isidro y seis personas más, todas principales: José Blas, José Huaringa, Esteban Cajahuaringa, Juan Chumbirisa, José Gabriel Yacsavilca y Juan Chumbipuma. Nótese que todos los apellidos son indígenas.

Hacía el final del texto, los alcaldes indígenas de Huarochirí expresaron varias intenciones: una disculpa, que es un cálculo político, apelando a esa "ingenuidad" ideológica construida en torno a ellos; una explicación que buscaba reparar su desobediencia; y también una coartada para curarse, en salud, de posibles represalias por hechos censurables que, aunque no aparecen en el documento, es bastante probable que hayan ocurrido, o más audaces aún, podían cometer si se tiene en cuenta que el documento finaliza con esta confesión de parte inquietante:

¡Hay Señor, que fuera de nosotros con los que siendo enbiados para nuestro consuelo llegan con sus excesos a exasperarnos y precipitarnos, sino tubieramos quien trabaje con amor cristiano haciéndonos conocer lo bueno y huir de lo malo a fin de que prosedamos hacia nuestra felicidad! El sacerdote que tenemos es el aun nos sacó del caos en el que estuvimos confundidos, y nos hiso entender que V. E. había venido dexando en Asia el nombre antiguo de Moises, y recibió el nuevo de San Martin, para libertar nuestra América (CDIP 1971, t. V, vol. 1, $323)$.

Las "cargas" y el "correo" fueron, como se ve, el hilo de una madeja más compleja que puso al descubierto el entramado ideológico que recubría ahora el enfrentamiento de tres sistemas de obediencia y soberanía política: aquel secular — proveniente del sistema de dominio colonial — el legado gaditano y las promesas republicanas, que pugnaban por insertarse en un tejido social ahora permeable por la creciente militarización de la región. Para los alcaldes constitucionales se trataba ahora de hallar espacios de confluencia entre las prácticas electorales gaditanas, sustentadas en valores de representación colectiva, y los ideales republicanos, aún abstractos. Nuevamente interesa explorar las estrategias de resistencia y confluencia frente a lo nuevo de parte de los diferentes grupos sociales en los Andes centrales. 
El documento, presumiblemente redactado por el sacerdote local, introduce un tercer elemento que ilumina una parte importante del horizonte mental e ideológico sobre el que se sostienen y que los diferencian de patriotas y realistas. Se trata de la centralidad de los párrocos locales y de ese amplio espectro ideológico doctrinal del catolicismo que ni patriotas y realistas objetaron; $\mathrm{y}$, por ello mismo, terminó por convertirse en un paraguas ideológico para guarnecerse de toda sospecha: "y por ultimo este religioso padece por resorte por que padecemos, y se alegra cuando nos alegramos, es el único alivio que tenemos por aora, que quedamos con el rogando a Dios" (CDIP 1971, t. V, vol. 1, 323).

Algo más, aquí asistimos a las primeras confrontaciones entre soberanías dispares que habrían de coexistir durante toda la guerra (Montoya 2019). Aquel liberalismo gaditano ya saboreado por los pueblos y la promesa republicana que era impuesta por un ejército de ocupación. Pero entre esta y aquella, existían extensos e inciertos márgenes de conflicto. Es de notarse que, en tanto la representación gaditana se sustentaba sobre una base de prácticas y usos culturales endógenos, y que calzaban en términos de continuidad al interior de la monarquía en sus dos modalidades — absolutista y liberal—, en cambio, es perceptible que, por provenir de la periferia, la independencia concedida y la soberanía que reclamaba por medio de las bayonetas patriotas fueran resistidas con las armas y en los discursos por extensos sectores de la plebe rural andina apenas iniciada la campaña (Montoya 2019). Y como se ha visto en este caso, por intermedio de una negociación sutil, y no por ello menos compleja y tirante. Pero ya se verá cómo, conforme se sucedían los hechos de armas y los fenómenos políticos y sociales, muchos pueblos de indios y mestizos desafiaron con las armas y en el discurso esa promesa republicana, y también se resistieron a seguir las banderas del rey.

Estos cuerpos armados de procedencia civil operaron en un territorio densamente poblado, donde la existencia de haciendas era minoritaria; más bien sus habitantes se distribuían en una extensa red de comunidades autónomas, compuestos por pequeños propietarios, con índices consistentes de alfabetización, por lo tanto, con acceso directo al potente flujo de noticias generadas por la dinámica de la guerra. De estos sectores saldrían los líderes guerrilleros, una mezcla de liderazgo carismático y de lealtades locales (Espinal 2020). La tropa estuvo compuesta por la plebe rural indígena y mestiza, donde se entrecruzan diversas ocupaciones, campesinos, arrieros, arrendatarios, peones, pastores. Otros vieron en la guerra una ocasión practica de 
aprovechamiento: había gente que huía de la justicia, como también sujetos que ya habían desarrollado cierto nivel de conciencia política, lo que veremos en seguida.

Otro elemento que distingue a esta región es la experiencia previa que tuvieron como testigos o como actores en la rebelión de Huánuco en 1812, y el efecto de la revolución del Cusco que llegó hasta Huamanga y se propaló en toda la región central bajo la forma de bandolerismo social y protestas localizadas, por lo menos hasta 1816 (Igue 2008). De otro lado, Tarma fue una ciudad tempranamente militarizada para contener las avanzadas de Juan Santos Atahualpa; de Tarma y los pueblos circunvecinos se había reclutado tropa para debelar la violenta insurrección en Huánuco. Por ello, son recurrentes en las fuentes la presencia de los "veteranos", milicianos con experiencia de combate y cierta formación militar, y que se remontaba a la reforma militar del siglo XVIII (Marchena 1992).

Y para explicar su conducta, considerar que estas milicias, al igual que el resto de la población, seguían con ritmos diferentes, y desde consideraciones convenidas, el curso de la revolución independentista continental. No estaban de ninguna manera aislados. Consumían y recreaban las noticias, los rumores ciertos o distorsionados, que traían y llevaban los arrieros. La gente especulaba. La única certeza que todos compartían, sin duda, era que los tiempos estaban revueltos, que el cambio y la alteración del orden ya era moneda corriente, que las jerarquías y los valores sociales estaban siendo cuestionados. Se abría un horizonte incierto para los sectores propietarios. Entre los subalternos, las expectativas estaban a la orden del día.

La hegemonía militar realista, desde 1821 en adelante, que controlaba las principales ciudades y centros poblados de la región, obligó a las milicias patriotas locales a replegarse hacia las partes altas, espacios que además de serles familiares, les resultaba la única posibilidad donde exhibir su compromiso por la independencia. Esta guerra de movimientos, conducida casi de manera autónoma por los líderes locales, desencadenó una compleja trama de discursos políticos. Un sorprendente lenguaje en el que se superponían nociones y categorías del antiguo régimen, y la nueva jerga ya decididamente republicana. Era, en realidad, el desembalse de un vocabulario liberal que hasta antes de la presencia de los libertadores había sido contenido por la censura virreinal.

Finalmente, se hace visible la centralidad y el protagonismo de miembros del bajo clero rural, en su rol de ideólogos e intelectuales funcionales en las 
localidades, y como actores colectivos sociales más que políticos. Estos personajes cumplieron el delicado encargo de representar, por intermedio de una retórica inédita, todas las formas de justificación ideológica que los pueblos precisaban para marcar su territorio y para hacer entender, sobre todo a los libertadores, que ellos, los pueblos a los que habían venido a redimir, poseían intereses concretos y una memoria social de sus deberes y obligaciones. Es decir, la puesta en movimiento del entramado ideológico cultural sobre el cual habrían de actuar en la guerra. Pero, a fin de cuentas, ¿podían haberse sustraído a intervenir en la guerra los grupos sociales que conformaban la plebe rural de una región que poseía antecedentes de movimientos sociales armados y una memoria social disidente en contra del sistema de dominio colonial?

\section{El ejército libertador y la incertidumbre de la independencia en Lima}

En la capital, luego de proclamada la independencia, la reciente instalación del Protectorado generó reacciones y acomodos entre los diferentes grupos sociales y núcleos de intereses compartidos que se iban constituyendo al paso y siguiendo la coyuntura de la guerra y el proceso político en curso. Por ello, una apreciación del Protectorado identificando a los actores políticos, siguiendo las acciones militares y el debate ideológico, también permite racionalizar la guerra en los Andes centrales.

El principal actor fue el Ejército Unido de los Andes, como garante de fuerza del régimen sanmartiniano. Una fuerza armada de ocupación que muy pronto, pasado el inicial entusiasmo, despertó inquietudes y resquemores entre todos los actores de la guerra e incluso en el seno de su Estado Mayor. La elite social propietaria había aceptado la formal proclamación de la independencia como un hecho consumado. El partido republicano reunía a un heterogéneo conjunto de grupos sociales compuesto de medianos y pequeños propietarios, intelectuales, profesionales y comerciantes; todos estos unidos por una ideología de diversa consistencia doctrinal y que había venido cohesionándose bajo la penumbra, por lo menos desde el inicio de la crisis imperial en 1808 . También la plebe limeña, sensible y atenta a consideraciones de sus propios intereses y que exhibieron puntos de vista políticos variables y poco estructurados. El populacho urbano, compuesto por miembros del lumpen limeño que, por efecto de la guerra y el aflojamiento de los mecanismos de control social, observaba a la expectativa el curso de la guerra para consumar actos 
de violencia social, robos, saqueos y atentados en contra de propietarios. Y, finalmente, las montoneras y guerrillas compuestas por mestizos, indios y otras castas, las exhibieron inusitados niveles de autonomía.

Pasado el inicial entusiasmo, el resquebrajamiento del mando en el Ejército Unido de los Andes estuvo atravesado por múltiples causas y circunstancias; entre ellas, la decisión de establecer una novedosa entidad política como nueva forma de gobierno en el Perú: el Protectorado. La decisión que tomó San Martín de establecer esta forma de gobierno fue criticada desde diferentes sectores de la incipiente clase política peruana poscolonial y también por parte de algunos sectores del propio ejército libertador. El argumento era que la Expedición Libertadora había venido al Perú para liquidar a los realistas y no para intervenir en la organización política y forma de gobierno que debía instalarse. Más aún cuando no se había concluido militarmente la independencia. De otro lado, es visible que San Martín y Monteagudo intentaron llevar adelante un régimen de tipo conservador. Esta iniciativa fue el resultado de la propia experiencia que habían tenido en los diferentes escenarios de la guerra contra los realistas en los que habían participado. Pero, sobre todo, por efecto de la anarquía que se había desatado en todos aquellos países en que luego de obtenerse la independencia, y al conformar regímenes republicanos sustentados en la soberanía popular y amplias libertades políticas, estas pronto derivaron en luchas civiles, desorden político y fragmentación territorial.

Este malestar entre los miembros del Estado Mayor se hizo evidente a propósito de la promulgación del Estatuto Provisional el 8 de octubre de 1821, primera fórmula de gobierno ejecutiva en el Perú luego de la formal proclamación de la independencia. Pero, además, la figura del Protectorado era ir contra la corriente, era situarse en la otra orilla y enfrentada a los gobiernos y regímenes republicanos ya establecidos en casi todo el continente. Y Monteagudo era plenamente consciente de aquel experimento. ${ }^{8}$

El propio jefe del Estado Mayor, general Gregorio de las Heras, en un oficio dirigido al supremo director del Estado y al Senado de Chile, le expresa que él había sido designado por San Martín como comandante en jefe, y que este debía su existencia a los Estados que habían financiado la Expedición Libertadora: Chile y las Provincias Unidas del Río de la Plata. Pero el conteni-

8 En su Memoria sobre los principios políticos que seguí en la administración del Perú y acontecimientos posteriores a mi separación, publicado en Quito, en marzo de 1823, da cuenta del estado económico, social y político del Perú, de sus costumbres y los impedimentos estructurales que existían e impedían el establecimiento de un régimen representativo y democrático. 
do de este informe es mucho más explícito, pues ya se vislumbra la existencia de un ambiente de tensión, desconcierto y desaprobación entre el comando de la tropa patriota por el modo en que San Martín y sus más cercanos colaboradores conducían la campaña libertadora. $Y$ estos son los términos y el comentario de Gregorio de las Heras a propósito del nuevo acto de sujeción que el Protectorado impuso al Ejercito Unido de los Andes por intermedio del Estatuto Provisional:

el mismo [el Estatuto Provisional] que se ha jurado obedecer por las tropas y clases de este Estado; y al que yo por mi y a nombre de las tropas de esas provincias y de las de Chile y Colombia, como pertenecientes a otras potencias, he prometido reconocer y obedecer en cuanto no se oponga a las órdenes que de los gobiernos de que dependo, como lo comprueban los documentos del Ministro de la Guerra, ante quienes presté mi compromiso (CDIP 1971, t. VI, vol. 2, 306-307).

Otro de los problemas que se anuncian es el conflicto por las interdependencias aún irresueltas entre los cuerpos del ejército patriota y los gobiernos que financiaron de, un lado, y por otro, la unidad del comando bajo la dirección del entonces recientemente creado Protectorado.

Otra coyuntura en que volvió a hacerse visible la confusión y resistencia del Ejército Unido de los Andes de someterse a la nueva estructura de mando diseñada por el régimen protectoral, fue con motivo del juramento que debían hacer algunos de los oficiales de mayor graduación ante la Orden del Sol, condecoración creada por el Protectorado para cohesionar ideológicamente a quienes se comprometieron con el proyecto aristocrático constitucional, pacientemente elaborado por la elite colonial limeña proindependentista. Este fue el informe y la consulta dirigida por Las Heras al supremo director de Chile Bernardo O'Higgins desde Lima el 10 de octubre de 1821:

incluyo a V. E. un exemplar del reglamento de la Orden del Sol, que se ha instituido en este Estado. Por su contenido se impondra V. E. que algunos oficiales de los cuerpos dependientes de esas Provincias, deben ser agraciados en su distintivo; y sin embargo que yo ofresco saber, en el juramento que en ella se previene, la obediencia que se debe a V. E. y el derecho que ese gobierno tiene sobre nuestras personas y operaciones, con todo, espero que V. E. se sirva dar el permiso necesario para que los agraciados puedan usar de la indicada insignia, o la que fuere más de su agrado (CDIP 1971, t. VI, vol. 2, 307). 
En realidad, el interés para establecer vínculos de entendimiento con la nobleza peruana lo expresó San Martín muy temprano. En una de sus primeras medidas, fechada en el mes de octubre en Pisco, el año 1820, señaló: "la nobleza peruana tiene sus timbres; justo es que los conserve. La nobleza peruana podrá usar sus antiguas armas variando los jeroglíficos que sean opuestos a los principios proclamados" (CDIP, t. X, 13). Es revelador que, apenas desembarcada la Expedición Libertadora, las señales públicas hayan sido muy claras, de lo que luego se intentó cimentar durante el Protectorado.

Pero estos testimonios también dan cuenta de la trayectoria y relación entre los Estados independientes recientemente constituidos y sus Fuerzas Armadas, el intento de los primeros por administrar, organizar y sujetar a ejércitos revolucionarios por naturaleza, depositarios efectivos de la soberanía y del gobierno, arrebatados en los campos de batalla a los realistas (Thibaud 2013). Como resultado de estas contradicciones y desavenencias, se puso en movimiento el rumor de una conspiración nada menos que para atentar en contra del general San Martín y destituirlo del mando (Castro 2011).

A un buen sector de los oficiales y la tropa que llegó con San Martín no les causó ninguna gracia comprobar cómo el Protectorado se proponía, nada más y nada menos, que conciliar el antagonismo social irreductible que oponía a aristócratas y plebeyos, a realistas y patriotas, y que había estado en el origen de la revolución continental. Era ir en contra de una tendencia continental ya consolidada. Los batallones del Ejército Unido fueron cuerpos revolucionarios que poseían ya tradiciones, emblemas, símbolos y héroes que habían ofrendado sus vidas en contra del despotismo, la arbitrariedad social y las jerarquías étnicas y de casta. Para estos hombres, esa fue la guerra que libraron por las independencias en diferentes regiones; es necesario recordarlo, de vez en vez. Era un ejército revolucionario y con una cultura política densa. Justamente, estos cuerpos protagonizarían motines, golpes de Estado, actos de insubordinación y todo tipo de excesos y atropellos en contra de poblaciones civiles (Montoya 2002). Es necesario considerar cómo al compás de la guerra se fueron decantando posiciones ideológicas entre todos los grupos sociales presentes en Lima, y la evolución de sus relaciones con una fuerza armada de ocupación.

En general, la guerra de la independencia del Perú fue escenario de diversas formas de intervención de estas tropas en el proceso político en curso. El golpe de Estado en contra del virrey Pezuela por parte del propio Estado Mayor realista. La defección del batallón realista Numancia y su pase al ejér- 
cito libertador. El golpe de Estado de parte de Riva Agüero y Santa Cruz en contra de la Junta Gubernativa, para lo cual fueron movilizados los restos del ejército libertador. La entrega del Real Felipe de parte de cuerpos patriotas encargados de su custodia en favor del ejército realista. Aquí estamos ante un complejo proceso en la definición de identidades políticas e ideológicas de estos ejércitos y el papel determinante que tuvo la guerra en dicho fenómeno. Lo particular aquí es que estos eventos se produjeron en un escenario que condensaba todo el ciclo revolucionario continental. Existe ahí un fenómeno de acumulación y aprendizaje, de decantación y depuración. Un laboratorio privilegiado, en el "nudo del imperio" (Mc Evoy 2015), que puso a prueba y en tensión diversas modalidades de acción e identidad política, territorial, cultural, militar y sus respectivas justificaciones ideológicas.

Si se considera que el Protectorado duró poco menos de un año, se entiende por qué no pudo subsistir, pues se propuso llevar un programa de gobierno y reformas imposible de verificar, justamente por la ambiciosa pretensión de sus ideólogos. ¿Era posible que este régimen subsistiera cuando desde su arribo a las costas peruanas ya había dado mensajes contundentes sobre sus pretensiones conciliatorias? Si se revisan los decretos y leyes que se publicaron, se podrá hallar una desproporción entre los medios y los fines. ${ }^{9}$ En realidad fue el idealismo doctrinario de los libertadores lo que paradójicamente los ató de manos. Deslumbrados por los rituales y festejos, las proclamas e inauguraciones, los libertadores se dejaron obnubilar y quedaron paralizados frente a los desafíos que la guerra sacaba a flote. El proyecto de independencia controlada se terminó ahogado en las pulcras reuniones de la Sociedad Patriótica. Esta dramática aspiración puede advertirse en el siguiente fragmento del discurso de apertura de la Sociedad Patriótica por parte de Monteagudo: "hagamos la guerra a los principios góticos, á las ideas absurdas, á las máximas serviles, en suma a la ignorancia, que es el sinónimo de esclavitud y anarquía" (Lorente 2005). ${ }^{10}$

Toda la retórica del régimen protectoral fue conducido por una frágil alianza de militares e intelectuales ilustrados por reformar la sociedad a punta de palabras y decretos. Hubo una sucesión de gestos y medidas por modernizar los usos y costumbres, de atender los reclamos y aspiraciones que el

9 Mark Thurner (2006), en la introducción de su libro Republicanos andinos, pone el énfasis en el afán refundacional que se realizó durante el Protectorado mediante una prolífica depuración y recambio de símbolos y emblemas, del nombre de entidades públicas y el relevo de alegorías que remitían al antiguo régimen.

10 También véase CDIP (1971, t. XIII, vol. 1, 448). 
ciclo revolucionario de la periferia continental había instalado como agenda social pendiente, además de la aceleración de expectativas y demandas de toda índole de todos los grupos sociales. El Protectorado se inició como una fiesta permanente. La Gaceta de Gobierno, aceitada por esa mente febril de Monteagudo, no cesaba de hacer públicos una asombrosa sucesión de decretos, leyes y medidas, que incluso lograron entusiasmar a no pocos historiadores contemporáneos. Da la impresión de que, en Lima, a propósito de la proclamación de la independencia, se escenificó uno de los rituales de transito más duraderos en el tiempo — justamente el régimen protectoral—, complejo, sofisticado y que exponía sintéticamente las aspiraciones materiales y subjetivas de todos los actores sociales. Lo antiguo y lo nuevo de la cultura y las sensibilidades sociales y estéticas fluyeron durante un régimen que mantuvo en vilo, aunque precariamente, todas las contradicciones que la guerra irremediablemente debía sacar a flote (CDIP 1971, t. XIII, vol. 1, 448).

Las diversas aproximaciones que hacia el protectorado han ensayado diferentes narrativas elaboradas, en estos dos siglos, se deben no solo a las conocidas estrategias historicistas y la mirada cambiante sobre la reflexión histórica en el tiempo, y al sujeto social que las enuncia y el lugar desde donde se elaboran. También contribuye el hecho innegable de haber sido un régimen de tránsito, brevísimo para los ambiciosos objetivos de sus conductores, donde se ensayaron idealmente, y desde la enunciación, todas las aspiraciones de la guerra separatista continental que confluyó en el "nudo del imperio", para usar una metáfora que ha ganado suerte. El Protectorado dio cabida e intentó resolver las demandas de todos los grupos sociales que habían admitido la proclamación de la independencia a la fuerza o por la persuasión. Y para los portadores de cada una de estas demandas y aspiraciones, el Protectorado fue concebido como hechura suya.

Allí se encuentra la aristocracia terrateniente limeña firmante del acta y lo que representaba, congregados alrededor del cabildo metropolitano y sus aliados de clase. Los comerciantes que no huyeron con La Serna y, por el contrario, apostaron su carta con un régimen que había dado señales de entendimiento. La amplia franja de republicanos de diversa procedencia social, que se sentían los verdaderos titulares de la fiesta independentista. Los sectores subalternos y el populacho compuesto de indios, mestizos, castas y esclavos que tenían demasiadas razones para frotarse las manos e intuir que un tiempo nuevo habíase inaugurado. Todos estos actores convinieron en dejar a un lado sus enconos étnicos y desavenencias materiales. Deslumbrados por la para- 
fernalia del régimen y la salida del virrey, dejaron que el tiempo de la guerra realice su obra con calma. Se tuvo que actualizar los irreductibles antagonismos de raza y de clase que el sistema de dominio colonial había sedimentado con método.

Una aproximación al ambiente político e ideológico de esa coyuntura exige admitir que esa fiesta permanente, y el conflicto que le siguió, se hizo público con motivo del debate entre republicanos y monárquicos al interior de la Sociedad Patriótica, y que fuera convocado - hay que insistir en ellopor un régimen de ocupación. Vale decirlo, con limitaciones y recortes de autonomía, debido a la fuerte presión ejercida por el autoritario ministro de Estado, el tucumano Bernardo Monteagudo. Esta convocatoria hizo parte de un programa mayor, cuyo objetivo fue instalar un régimen aristocrático, conservador y con fuertes restricciones a las libertades políticas. A ello apuntaba también la manipulación en las elecciones para el Congreso y la deliberada represión a prominentes miembros del partido republicano (Montoya 2002, Paniagua 2003). Como se sabe, estas propensiones monárquicas de los ilustrados que rodeaban a San Martín fueron severamente impugnadas y derrotadas en las calles de Lima por intermedio de movilizaciones populares y resistencias de la elite criolla antirrealista, las que concluyeron con la expulsión de Monteagudo a fines de julio de 1822. Sin duda, contribuyó a esta derrota el primer texto redactado por el Solitario de Sayán, Faustino Sánchez Carrión, en abril del mismo año, y que circuló de mano en mano entre la vanguardia republicana opositora. Este documento posee una fuerte y densa aura de pedagogía política, pues también fue concebido para movilizar voluntades $\mathbf{y}$ ganar la opinión pública. Al inicio de su texto, Sánchez Carrión se cuidó por dejar sentado desde qué posición ingresaba al debate "he entrado en una agitación extraordinaria desde el momento, en que leí la Gaceta; porque, amigo mío, también soy de la familia, y es muy regular que, al discutirse puntos relativos a su conservación y felicidad, levante mi cabeza, y siquiera pregunte lo que sucede en casa" (CDIP 1971, t. I, vol. 9, 349-350).

¿Desde la marginalidad? De ninguna manera. Más bien desde la oposición plebeya católica republicana, pues al situarse Sánchez Carrión fuera de la Sociedad Patriótica, lo que en realidad consuma es un audaz movimiento táctico; desprivatizar el debate del círculo ilustrado y volcarlo a la prensa, generando opinión pública e impresa, consolidando y recogiendo la creciente animadversión pública ya instalada en contra del Protectorado (Mc Evoy 1999). Sus dos cartas publicadas en la prensa lograron así galvanizar las diferencias 
internas entre la oposición política al régimen. Antes había ocupado posiciones discretas en el Gobierno; ${ }^{11}$ y en ello radica su capacidad de maniobra, no salir del proceso político en curso, pues tampoco era ajeno a la lucha ideológica, como lo demostró durante las elecciones del año 1813 (CDIP 1971, t. I, vol. 9, 56-57). Y otra prueba de su talento político fue el haberse situado como el colaborador peruano más cercano e influyente de Bolívar hasta concluir la guerra, ejerciendo la cartera de ministro general de Negocios.

Como ya fue señalado, los cuestionamientos de Monteagudo a las proposiciones de Sánchez Carrión las publicó aquel durante su destierro en Quito el año 1823. De la lectura de su Memoria se puede colegir que se trata básicamente de su defensa y una justificación sobre su desempeño como ministro de Estado y alter ego de San Martín. ${ }^{12}$ Si bien la controversia se inició en la Sociedad Patriótica (enero de 1822), esta no prosperó debido a la crisis política y el estancamiento militar. Sin embargo, el debate siguió su curso por otros medios: la prensa, el exilio, la continuación de la guerra, la caída de Monteagudo del poder y el ascenso político de Sánchez Carrión.

Las consideraciones de Monteagudo fluyen desde su condición de estadista $y$, por lo tanto, son precauciones desde el poder. Aun se puede agregar que son verificaciones del fracaso de un actor sobresaliente, que ha trajinado diferentes escenarios políticos y frentes militares de la ola emancipadora del continente. Por lo tanto, representa una tendencia de pensamiento. De otro modo no se entiende el dramático final de su memoria. Una advertencia en contra de toda forma de idealismo político y alienación doctrinaria:

Pero si algunos hombres llenos de virtudes patrióticas, acreditados en los combates o en la dirección de los negocios, emplean su influjo en hacer abrazar a los pueblos teorías que no pueden subsistir y que perjudican a sus mismos votos, la prosperidad reclamará contra ellos... Malditas sean sus virtudes: ellas han causado la ruina de su patria (CDIP 1971, t. XIII, vol. 2, 293).

Si se toman en cuenta las fechas entre este texto y la actividad de Sánchez Carrión redactando las bases de la primera Constitución, podemos deducir

11 Fue miembro de la Junta Conservadora de la Libertad de Imprenta (CDIP 1971, t. XIII, vol. 2, 485) . También fue fiscal (20-04-1822) de "una comisión de vigilancia que conocerá privadamente de las causas de los españoles"; es decir, en la coyuntura de mayor represión contra los españoles (CDIP 1971, t. XIII, vol. 1, 370-371).

12 El mismo título así lo confirma: "Bernardo Monteagudo, Memoria sobre los principios políticos que seguí en la administración del Perú y acontecimientos posteriores a mi separación" (CDIP 1971, t. XIII, vol. 2, $264-293)$. 
que es una advertencia y, por lo tanto, el debate seguía su curso. Como se ha señalado, el profesor carolino, al situarse desde la oposición civil republicana a los planes monárquicos, extrema sus pretensiones desde los intereses de las mayorías sociales de su época y a quienes se propone representar. Sus cavilaciones son el resultado de un pensamiento situado. Así se entiende que haya formulado una de las aspiraciones más radicales de democracia social en los albores de la república:

Un autor, célebre por la extraordinaria liberalidad de sus principios, y por la fuerza de su raciocinio, quiere que el gobierno se aproxime, cuanto sea posible, a la sociedad. Quiere poco; yo quisiera, que el gobierno del Perú fuese una misma cosa que la sociedad peruana, así como un vaso esférico es lo mismo que un vaso con figura esférica (CDIP 1971, t. I, vol. 9, 353).

¿Cómo entender una aspiración de esta envergadura si no es desde la resistencia al autoritarismo, o una dictadura como fue el Protectorado, pero que fue necesario para liquidar a la oposición civil prorrealista, fortalecida por el triunfo de las armas del rey en la batalla de Macacona de Ica en abril de 1822 ?

La destitución a Monteagudo fue el anuncio del fin del Protectorado. Y este desenlace inesperado fue el que precipitó la naturaleza ideológica de la representación del primer Congreso Constituyente. Una asamblea que no representaba a la totalidad de un país cuyas ricas e importantes regiones del centro y sur andino aún estaban bajo control realista. Su instrumento de gobierno, conformado por tres miembros de la asamblea —José de la Mar, Felipe A. Alvarado y el Conde de Vista Florida-, pronto mostró las limitaciones de un Poder Ejecutivo atado a las deliberaciones y vaivenes del Poder Legislativo en que empieza a cobrar relevancia la figura de Luna Pizarro. "El poder detrás del poder", como gustaba autodefinirse según Basadre. La memoria de Monteagudo, fechada el 17 de marzo de 1823, en Quito, recoge este conjunto de elementos que deben ser considerados a la hora de explicar sus alcances. Para esa fecha ya se habían producido dos acontecimientos decisivos: la derrota militar de los patriotas en Moquegua y Tarata, de fines de enero, y el golpe de Estado de Riva Agüero contra el Congreso en febrero del fatídico año de 1823. Cuatro meses después, Lima sería ocupada por las banderas del rey. Y son estos trágicos eventos políticos y militares los que nutren el profundo pesimismo, no exento de realismo por parte de Monteagudo, hacia todas las formas de regímenes republicanos y democráticos. En cambio, a Sánchez 
Carrión aquel cuadro lo acercó a Bolívar y a suscribir la dictadura como medida excepcional y temporal para finalizar la guerra.

Un elemento básico que da cuenta sobre las divergencias tácticas y estratégicas de toda índole entre el Protectorado de San Martín y la dictadura de Bolívar es que el primero ejerció el poder desde Lima, en tanto que Bolívar se parapetó en los Andes norcentrales. Monteagudo y Sánchez Carrión reprodujeron esa lógica. El tucumano se propuso ilustrar una ciudad conservadora y cortesana, mientras que el Solitario de Sayán, pese a su salud endeble, logró trasponer los Andes una y otra vez. No fueron, pues, simples estilos de combinar guerra y gobierno; fueron estrategias disimiles que provenían de diagnósticos contrapuestos, atendiendo, por cierto, a circunstancias militares y políticas específicas. 


\section{Referencias bibliográficas}

Castro, J. L. 2011. El secreto de los libertadores. Lima: Fondo Editorial de la Universidad Ricardo Palma.

Castro, J. L. 2015. José Ramón Rodil en el Callao 1824-1826: ¿recalcitrante? ¿monarquista obseso? ¿hombre de honor? En VI Congreso Internacional. Hacia el Bicentenario de la Independencia. Lima: Fondo Editorial de la Universidad Nacional Mayor de San Marcos.

Colección Documental de la Independencia del Perú (CDIP). 1971. La acción patriótica del pueblo en la emancipación. Guerrillas y montoneras (varios tomos) Lima: Colección Nacional del Sesquicentenario de la Independencia del Perú.

Escanilla Huerta, S. 2012. El desafío al orden. Bandolerismo y guerrillas en los inicios de la independencia. Perú 1820-1821. En D. Morán, S. Escanilla Huerta, y A. Silveira (Eds.). Plebe, sociabilidad y revolución. El Perú y Río de la Plata en el contexto de las guerra de Independencia (pp. 35-64). Lima: Grupo Gráfico del Piero.

Escanilla Huerta, S. 2013. De la lealtad a la negociación a la obediencia. Transformaciones políticas durante la guerra de independencia en el Perú. El caso del pueblo de Huacho. XIV Jornadas interescuelas de Historia. Mendoza: Universidad Nacional de Cuyo. Departamento de Historia de la Facultad de Filosofía y Letras.

Espinal, V. 2020. Guerra y guerrillas en los Andes centrales. Perú, 1820-1824 (tesis de licenciatura). Lima: Universidad Nacional Mayor de San Marcos.

Glave, L. M. 2002. Un héroe fragmentado. El cura muñecas y la historiografía andina. Red de Revistas Cientificas de América Latina, el Caribe, España y Portugal. Sistema de Información Cientifica-Andes, (13).

Glave, L. M. 2005. Las otras rebeliones: cultura popular e independencias. Anuario de estudios Americanos, 62 (1).

Igue, J. L. 2008. Bandolerismo, patriotismo y etnicidad poscolonial: los morochucos de Cangallo, Ayacucho, en las guerras de independencia, 1814-1824. Lima: Fondo Editorial de la Pontifica Universidad Católica del Perú.

Lorente, S. 2005. Sebastián Lorente. Escritos fundacionales de historia peruana. Lima COFIDE, Fondo Editorial de la Universidad Nacional Mayor de San Marcos.

Marchena, J. 1992. Ejército y milicias en el mundo colonial americano. Madrid: Mapfre.

Mc Evoy, C. 1999. El motín de las palabras: la caída de Bernardo Monteagudo y la forja de la cultura política limeña (1821-1822). En C. McEvoy. Forjando la nación. Ensayos de historia republicana (pp. 1-60). Lima: Fondo Editorial de la Pontificia Universidad Católica del Perú. 
Mc Evoy, C. 2015. De la República imaginada a la República de las armas. Lima: Instituto de Estudios Peruanos.

Méndez, C. 2014. La república plebeya. Huanta y la formación del Estado peruano, 1820.1850. Lima: Instituto de Estudios Peruanos.

Montoya, G. 2020. La independencia controlada. Guerra, gobierno y revolución en los Andes. Lima: Sequilao Editores.

Montoya, G. 2002. La independencia del Perú y el fantasma de la revolución. Lima: Instituto de Estudios Peruanos.

Montoya, G. 2018. La tradición republicana en Huánuco. Diálogos entre historia y política. Huánuco: AIA, APEC.

Montoya, G. 2006. Prensa popular y cultura política durante la iniciación de la República. Monárquicos republicanos, heterodoxos y católicos. Uku Pacha, (10).

Ortemberg, P. 2014. Rituales de poder en Lima (1735-1828). Lima: Fondo Editorial de la Pontificia Universidad Católica del Perú.

Ortemberg, P. 2012. Las vírgenes generalas: acción guerrera y práctica religiosa en las campañas del Alto Perú y el Río de la Plata (1810-1818). Boletín del Instituto de Historia Argentina y Americana «Dr. Emilio Ravignani», (35-36).

Peralta, V. 2010. La independencia y la cultura política peruana (1808-1821). Lima: Instituto de Estudios Peruanos.

Peralta, V. 2008. El impacto de las Corte de Cádiz en el Perú: un balance historiográfico. Revista de Indias, LXVIII (242), 67-96.

Quiroz, F. 2016. Regiones, tiempo e independencia en los Andes. En VI Congreso Internacional. Hacia el Bicentenario de la Independencia. Lima: Fondo Editorial de la Universidad Nacional Mayor de San Marcos.

Quiroz, F. 2015. El centro del país en guerra sin cuartel. Independencia y guerrillas. Revista Historia, 1 (2).

Roca, J. S. 1866. Apuntes póstumos: relación histórica de la primera campaña del general Arenales a la Sierra del Perú, en 1820. La Revista de Buenos Aires. Historia Americana, Literatura y Derechos, (42-42-44).

Sala i Vila, N. 1993. La Constitución de Cádiz y su impacto en el gobierno de las comunidades indígenas en el virreinato del Perú. Boletín Americanista, (33), 51-70.

Sala i Vila, N. 2011. El trienio liberal en el virreinato peruano: los ayuntamientos contitucionales de Arequipa, Cusco y Huamanga, 1820-1824. Revista de Indias, LXXI (253), 637-823.

Spalding, K. 2014. El diario histórico de Sebastián Franco de Melo. El levantamiento de Huarochirí de 1750. Lima: Centro Peruano de Estudios Culturales. 
46 | Discursos Del Sur / Gistavo Montoya Rivas y YizZA Delgado Nery de VITA

Thibaud, C. 2003. República en armas. Los ejércitos bolivaianos en la guerra de independencia en Colombia y Venezuela. Bogotá, Lima: Planeta, IFEA.

Thibaud, C. 2005. Formas de guerra y mutación el Ejército durante la guerra de independencia en Colombia y Venezuela. En J. Rodríguez (Ed.). Revolución, independencia y las nuevas naciones de América. Madrid: Mapfre.

Thurner, M. 2006. Republicanos andinos. Lima: Instituto de Estudios Peruanos, CBC.

Walker, C. 1999. De Túpac Amaru a Gamarra. Cusco y la formación del Perú republicano 1780-1840. Lima: Instituto de Estudios Peruanos.

Walker, C. 2015. La rebelión de Túpac Amaru. Lima: Instituto de Estudios Peruanos. 